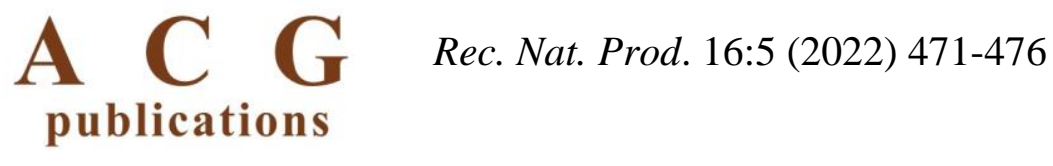

records of natural products

\title{
A New Benzophenone Derivative from the Endophyte Shiraia sp. BYJB-1
}

\section{Dekun Chen $\oplus^{1,2}$, Sha Zhang $\oplus^{1,2}$, Min Kuang $\oplus^{1,2}$, Weiwei Peng $\oplus^{1,2}$, Jianbing Tan $\oplus^{1,2}$, Wenxuan Wang $\oplus^{1,2}$, Fenghua Kang $\oplus^{1,2}$, Zhenxing Zou $\oplus^{1,2^{*}}$ and Kangping $\mathrm{Xu} \oplus^{1,2^{*}}$}

\author{
${ }^{1}$ Xiangya School of Pharmaceutical Sciences, Central South University, Changsha 410013, P. R. \\ China
}

${ }^{2}$ Hunan Key Laboratory of Diagnostic and Therapeutic Drug Research for Chronic Diseases, Central South University, Changsha 410013, P. R. China

(Received November 18, 2021; Revised January 23, 2022 Accepted February 02, 2022)

\begin{abstract}
A new benzophenone derivative, shiraone A (1), along with seven known compounds, linchenxantone (2), 4-hydroxymellein (3), hypocrellin A (4), hypocrellin B (5), 9,11-dehydroergosterol peroxide (6), ergosteroal peroxide (7), and lactariolide I (8), were isolated from the cultures of Shiraia sp. BYJB-1, a fungus from the leaves of the medicinal plant Selaginella delicatula. The structures of these compounds were established via extensive spectroscopic techniques, including 1D/2D NMR, HRESIMS and through comparison with data reported in the literatures. In addition, the cytotoxic activities and antibacterial activities of compounds 1-8 were evaluated, and compounds $\mathbf{6}$ and $\mathbf{7}$ exhibited moderate cytotoxic activities against SMMC7721 cell line with $\mathrm{IC}_{50}$ values of 25.9 and $45.8 \mu \mathrm{M}$ respectively.
\end{abstract}

Keywords: Endophytic fungus; Shiraia sp.; benzophenone; cytotoxic activity; antibacterial activity. (2022 ACG Publications. All right reserved.

\section{Introduction}

As a class of microbial community symbiotic with host plants, a number of endophytic fungi could synthetize bioactive secondary metabolites which assist the host plants in protection and survival against various biotic and abiotic factors (i.e., pest, drought) [1]. Furthermore, some of these metabolites are very valuable as lead compounds for novel drug research [2,3]. As part of our continuous commitment to discover structurally unique and biologically active natural products from medicinal plants and endophytic fungi, Shiraia sp. BYJB-1 was isolated for the first time from the Selaginella delicatula, a traditional medicinal plant documented in Chinese Pharmacopoeia [4] that showed have a variety of medicinal values such as treat amenorrhea, dysmenorrhea, cancer defect, falling and fluttering injury [5]. Plant-derived fungi of the genus Shiraia are reported to be producers of various secondary metabolites including perylenequinones, polysaccharides, sterols and so on,

\footnotetext{
"Corresponding author: E-Mail: zouzhenxing@ csu.edu.cn (Z.Zou); xukp395@csu.edu.cn (K. Xu)
} 
which have been shown to have antibacterial, antitumor and antioxidant activities [6-10]. A chemical investigation on the ethyl acetate extract of the endophytic fungus Shiraia sp. BYJB-1 led to the isolation of one new benzophenone derivative (1), and seven known compounds (2-8). To our knowledge, compounds $\mathbf{1 - 3}$ and $\mathbf{8}$ were obtained from the genus Shiraia for the first time. Herein, we describe the fermentation, isolation, structure elucidation, in vitro cytotoxic and antibacterial activities of these compounds.

\section{Materials and Methods}

\subsection{General Experimental Procedures}

Exact mass and molecular formulas were obtained with Agilent 6500 series Q-TOF mass spectrometer (Agilent, Singapore) analyser with positive ion mode. 1D and 2D NMR spectra were measured on a Bruker AVIII-600 spectrometer (Bruker, Karlsruhe, Germany) and using TMS as an internal standard. The reversed-phase preparative HPLC was conducted using an Agilent 1100 (Agilent Technologies, California, USA) instrument connected to a Innoval ODS-2 column ( $5 \mu \mathrm{m}, 10$ $\mathrm{mm} \times 250 \mathrm{~mm}$ ) with a VWD detector. Silica gel (80-100 and 200-300 mesh, Qingdao Marine Chemical Factory, Qingdao, China), macroporous resin (HPD-100, Hebei, China), Sephadex LH-20 (Toyopearl Tosoh, Tokyo, Japan) and $\mathrm{C}_{18}$ reversed-phase silica gel (50 $\mu \mathrm{m}$, Fuji, Kasugai, Japan) were used for column chromatography. All solvents were of analytical grade.

\subsection{Fungal Material}

The fungal strain Shiraia sp. BYJB-1 was isolated from the leaves of Selaginella delicatula, collected in Huangsang nature reserve in Shaoyang city, Hunan Province of China, in July 2019. The fungus was identified as Shiraia sp. BYJB-1 through the sequence analysis of rDNA ITS region, and the sequence of its rDNA region had been submitted to GenBank (Accession No. 7X7M35MH016). Moreover, the strain was deposited in Xiangya School of Pharmaceutical Sciences, Central South University.

\subsection{Fermentation, Extraction and Isolation}

The fungus was cultured in solid medium, which was prepared by autoclaving each $500 \mathrm{~mL}$ conical flask with $250 \mathrm{~g}$ of rice and $300 \mathrm{~mL}$ of ultrapure water in it. The fermentation was performed in 20 flasks under static conditions at a constant temperature of $28{ }^{\circ} \mathrm{C}$ for a month. The fungal culture was extracted with ethyl acetate added to each flask, and the extract was subsequently dried under vacuum to afford $60.2 \mathrm{~g}$.

The crude extract was subjected to macroporous resin column chromatography eluting with EtOH- $\mathrm{H}_{2} \mathrm{O}$ (v/v, 20:80-0:100) to give three fractions (Fr. A to Fr. C). Fr. B (25.7 g) was separated on a silica gel CC eluting with PE-EtOAc-MeOH (v/v/v, 100:0:0-0:0:100) to obtain 11 fractions (Fr. B-1 to Fr. B-11). Fr. B-5 (0.9 g) was separated by Sephadex LH-20 column to provide 6 subfractions, and Fr. B-5-4 (0.2 g) was further purified by prep-HPLC with $\mathrm{MeCN}^{-} \mathrm{H}_{2} \mathrm{O}(0-25 \mathrm{~min}, 50-70 \%, 3 \mathrm{~mL} / \mathrm{min})$ to obtain compound $3\left(3.6 \mathrm{mg}, t_{\mathrm{R}}=17.5 \mathrm{~min}\right)$. Fr. B-5-5 was purified by prep-HPLC with $\mathrm{MeCN}-\mathrm{H}_{2} \mathrm{O}$ (0-20 min, 70-95\%, $3 \mathrm{~mL} / \mathrm{min})$ to obtain compound $8\left(4.3 \mathrm{mg}, t_{\mathrm{R}}=18 \mathrm{~min}\right)$. Fr. B-2 (1.2 g) was

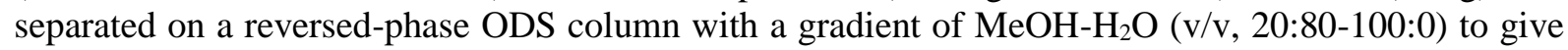
four subfractions (Fr. B-2-1 to Fr. B-2-4). Fr. B-2-2 (0.3 g) was further purified by prep-HPLC with $\mathrm{MeCN}-\mathrm{H}_{2} \mathrm{O}(0-30 \mathrm{~min}, 30-60 \%, 3 \mathrm{~mL} / \mathrm{min})$ to obtain compounds $1\left(3.5 \mathrm{mg}, t_{\mathrm{R}}=15.5 \mathrm{~min}\right)$ and $2(5.6$ $\left.\mathrm{mg}, t_{\mathrm{R}}=18.7 \mathrm{~min}\right)$. Fr. B-2-4 was purified by prep-HPLC with $\mathrm{MeCN}_{-} \mathrm{H}_{2} \mathrm{O}(0-30 \mathrm{~min}, 80-95 \%, 3$ $\mathrm{mL} / \mathrm{min})$ to obtain compounds $6\left(6.9 \mathrm{mg}, t_{\mathrm{R}}=22.8 \mathrm{~min}\right)$ and $7\left(7.6 \mathrm{mg}, t_{\mathrm{R}}=27.5 \mathrm{~min}\right)$. Fr. B-11 was performed on Sephadex LH-20 column to provide 3 subfractions, and Fr. B-11-1 (0.2 g) was then purified by prep-HPLC with $\mathrm{MeCN}-\mathrm{H}_{2} \mathrm{O}(0-30 \mathrm{~min}, 70-95 \%, 3 \mathrm{~mL} / \mathrm{min})$ to give compounds 4 (4.8 $\left.\mathrm{mg}, t_{\mathrm{R}}=19.2 \mathrm{~min}\right)$ and $\mathbf{5}\left(4.2 \mathrm{mg}, t_{\mathrm{R}}=24.1 \mathrm{~min}\right)$. 


\subsection{Cytotoxicity and Antimicrobial Activity}

Cytotoxicity of compounds 1-8 were tested against two human hepatoma cell lines (HepG2 and SMMC7721) using a microplate 3-(4,5-dimethylth-iazole-2-yl)-2,5-diphenyltetrazolium bromide (MTT) assay. Briefly, the cell lines were cultured in RPMI-1640 medium with $10 \%$ fetal bovine serum and $100 \mathrm{U} / \mathrm{mL}$ penicillin/streptomycin at $37{ }^{\circ} \mathrm{C}$. The suspended cells $(100 \mu \mathrm{L})$ with an initial density of $1 \times 10^{5}$ cells $/ \mathrm{mL}$ were seeded into each well of a 96-well microplate and put in 37 at $5 \% \mathrm{CO}_{2}$ condition to incubate for $24 \mathrm{~h}$. After that, the cells were treated with the tested compounds of concentrations ranging from 6.25 to $100 \mu \mathrm{M}$. The cells were further cultured for $48 \mathrm{~h}$, and then $50 \mu \mathrm{L}$ of MTT $(2 \mathrm{mg} / \mathrm{mL})$ was added to each well. After 4 hour later, DMSO $(200 \mu \mathrm{L} /$ well $)$ was added to dissolve the formazan crystals, and the absorbance was measured at $567 \mathrm{~nm}$. The inhibition rates were calculated by the formula: Inhibition rate $=1-$ the mean OD of the medicated group/the mean OD of the solvent control group. Sorafenib and DMSO were used as positive and negative control. The experiments were carried out in triplicate.

\subsection{Cytotoxicity and Antimicrobial Activity}

Antimicrobial activities of compounds 1-8 were evaluated against MRSA and E. coli. The determinations of MIC values were carried out by the Microbroth dilution method in Mueller-Hinton broth medium (MHB) [11]. The clinical drugs Vancomycin and Kanamycin were used as the positive controls. Optical density values for cell concentrations were recorded at $600 \mathrm{~nm}$ using a UV-6000 spectrophotometer (MEYASH, Shanghai, China).<smiles>COc1cc(C)c(C(=O)c2cc(OC)c(OC)c(OC)c2)c(O)c1</smiles><smiles></smiles>

4<smiles>COc1cc(C)c2c(=O)c3c(O)cc(OC)cc3oc2c1</smiles>

2<smiles>CC1OC(=O)c2c(O)cccc2C1O</smiles><smiles></smiles>

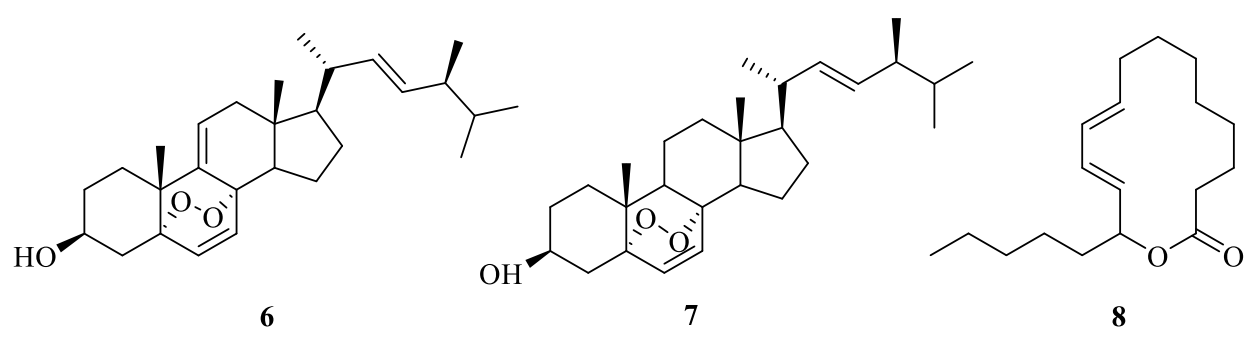

Figure 1. Structures of compounds 1-8 


\section{Results and Discussion}

\subsection{Structure Elucidation}

Compound 1 was obtained as a light yellow powder, and its molecular formula was determined as $\mathrm{C}_{18} \mathrm{H}_{20} \mathrm{O}_{6}$ based on HRESIMS ion peaks at $\mathrm{m} / \mathrm{z} 333.1340[\mathrm{M}+\mathrm{H}]^{+}$and $355.1152[\mathrm{M}+$ $\mathrm{Na}]^{+}$(calcd for $\mathrm{C}_{18} \mathrm{H}_{20} \mathrm{O}_{6}, 333.1338[\mathrm{M}+\mathrm{H}]^{+}, 355.1158[\mathrm{M}+\mathrm{Na}]^{+}$), indicating 9 degrees of unsaturation. The ${ }^{1} \mathrm{H}-\mathrm{NMR}$ spectrum (Table 1 ) of 1 showed two pairs of meta coupling aromatic protons at $\delta_{\mathrm{H}} 6.33\left(1 \mathrm{H}, \mathrm{d}, J=2.4 \mathrm{~Hz}, \mathrm{H}-3^{\prime}\right), 6.30(2 \mathrm{H}, \mathrm{s}, \mathrm{H}-2$ and $\mathrm{H}-6)$ and $6.26(1 \mathrm{H}, \mathrm{d}, J=2.4 \mathrm{~Hz}, \mathrm{H}-$ $\left.5^{\prime}\right)$, one exchangeable proton at $\delta_{\mathrm{H}} 13.10\left(1 \mathrm{H}, \mathrm{s}, 2^{\prime}-\mathrm{OH}\right)$, four methoxyl protons signal at $\delta_{\mathrm{H}} 3.82,3.78$, $3.68\left(12 \mathrm{H}, \mathrm{s}, \mathrm{H}-9, \mathrm{H}-7^{\prime}, \mathrm{H}-8\right.$, and $\left.\mathrm{H}-10\right)$, and one methyl protons signal at $\delta_{\mathrm{H}} 1.89\left(3 \mathrm{H}, \mathrm{s}, \mathrm{H}-8^{\prime}\right)$. The ${ }^{13} \mathrm{C}-\mathrm{NMR}$ spectrum (Table 1) of $\mathbf{1}$ exhibited 15 carbon resonances (includes three sets of overlapping carbon signals) consist of one ketone carbonyl carbon signal at $\delta_{\mathrm{C}} 199.2(\mathrm{C}-7)$, two benzene ring carbon signals at $\delta_{\mathrm{C}} 166.5,164.9,163.0,157.9,143.5,117.2,114.9,111.6,100.0$, and 92.1 (C-1 to C6 , and C-1' to C-6'), four methoxyl group carbon signals at $\delta_{\mathrm{C}} 56.8,56.8,56.4$ and 56.4 (C-8 to C-10, and $\left.\mathrm{C}^{-} 7^{\prime}\right)$, and one methyl carbon on the benzene ring signal at $\delta_{\mathrm{C}} 22.4\left(\mathrm{C}-8^{\prime}\right)$. Based on the 1D NMR data, compound $\mathbf{1}$ is suggested to be a benzophenone derivative, in which there is a symmetrical benzene ring.

Construction of the structure for $\mathbf{1}$ was accomplished by interpretation of 2D NMR data (Figure 2). In the HMBC spectrum of $\mathbf{1}$, the aromatic protons at $\delta_{\mathrm{H}} 6.30(\mathrm{H}-2$ and $\mathrm{H}-6)$ showed crosspeaks with the carbonyl carbon at $\delta_{\mathrm{C}} 199.2(\mathrm{C}-7)$ and three $O$-linked carbon signals at $\delta_{\mathrm{C}} 163.0$ and 157.9 (C-4, C-3, and C-5), while the aromatic protons at $\delta_{\mathrm{H}} 6.33$ and $6.26\left(\mathrm{H}-3^{\prime}\right.$ and $\left.\mathrm{H}-5^{\prime}\right)$ were correlated with a quaternary at $\delta_{\mathrm{C}} 143.5\left(\mathrm{C}-1^{\prime}\right)$ and a O-linked carbon at $\delta_{\mathrm{C}} 166.5\left(\mathrm{C}-2^{\prime}\right)$. The H-5' was correlated with a benzyl carbon signal at $\delta_{\mathrm{C}} 164.9\left(\mathrm{C}-4^{\prime}\right)$. The benzyl carbon at $\delta_{\mathrm{C}} 22.4\left(\mathrm{C}-8^{\prime}\right)$ showed cross-peaks with the $\mathrm{C}-5^{\prime}$ and quaternary $\mathrm{C}-1^{\prime}$ as well. According to the HMBC correlations of methoxy protons with $O$-linked carbons, the methoxy groups were placed at C-3, C-4, C-5, and C-4', and the hydroxyl was placed at C-2'. Therefore, the compound $\mathbf{1}$ was identified as (2-hydroxy-4methoxy-6-methylphenyl)(3,4,5-trimethoxyphenyl) methanone and named as shiraone A.

A putative biosynthetic pathway to $\mathbf{1}$ is presented in (Scheme 1). The key intermediates 3,4,5trimethoxybenzoic acid (I) was obtained by shikimic acid pathway. And the other key intermediates 2hydroxy-4-methoxy-6-methylbenzoic acid (II) was yielded by acetate-malonate pathway. Finally, compound 1 was obtained through a series of biosynthesis with the 3,4,5-trimethoxybenzoic acid and 2-hydroxy-4-methoxy-6-methylbenzoic acid.

The known compounds $\mathbf{2 - 8}$ were isolated identified as linchenxantone (2) [12], 4-hydroxymellein (3) [13], hypocrellin A (4) [6], hypocrellin B (5) [6], 9,11-dehydroergosterol peroxide (6) [14], ergosteroal peroxide (7) [15], and lactariolide I (8) [16] by comparing their spectroscopic data with those reported in literatures.

Compounds 1-8 were evaluated for their cytotoxic activities against SMMC7721 and HepG2 hepatoma cell lines (Table S1), and antibacterial activities against MRSA and E. coil (Table S2). Among them, compound 6 showed moderate cytotoxicity against SMMC7721 $\left(\mathrm{IC}_{50}=25.94 \pm 2.07\right.$ $\mu \mathrm{M})$ and $\mathrm{HepG} 2\left(\mathrm{IC}_{50}=50.48 \pm 1.94 \mu \mathrm{M}\right)$. In addition, compounds 6-8 displayed weak antibacterial activities against MRSA, and the MIC values were $62.5 \mu \mathrm{g} / \mathrm{mL}$.

In summary, one new benzophenone derivative, shiraone A (1), was isolated and identified, along with four known compounds (2-8), in which compounds 1-3 and $\mathbf{8}$ were isolated from this genus for the first time. The cytotoxic activities against two human hepatoma cell lines (HepG2 and SMMC7721) and antibacterial activities against MRSA and E. coli were evaluated. The results not only enriched the study on the chemical constituents of Shiraia genus, but also indicated that endophytes, especially isolated from medical plants, still play a very significant role in discovering structurally unique and biologically active natural products. 
Table 1. ${ }^{1} \mathrm{H}(600 \mathrm{MHz})$ and ${ }^{13} \mathrm{C}(150 \mathrm{MHz})$ NMR data for compound $\mathbf{1}$ (DMSO- $d_{6}, \delta$ in ppm, $J$ in $\mathrm{Hz}$ )

\begin{tabular}{cccccc}
\hline Position $(\mathbf{H})$ & $\boldsymbol{\delta}_{\mathbf{H}}(\boldsymbol{J}$ in Hz) & $\boldsymbol{\delta}_{\mathbf{C}}$ & Position $(\mathbf{H})$ & $\boldsymbol{\delta}_{\mathbf{H}}(\boldsymbol{J}$ in Hz) & $\boldsymbol{\delta}_{\mathbf{C}}$ \\
\hline 1 & & 114.9 & $1^{\prime}$ & & 117.2 \\
2 & $6.30 \mathrm{~s}$ & 92.1 & $2^{\prime}$ & & 166.5 \\
3 & & 157.9 & $3^{\prime}$ & $6.33 \mathrm{~d}(2.4)$ & 100.0 \\
4 & & 163.0 & $4^{\prime}$ & & 164.9 \\
5 & & 157.9 & $5^{\prime}$ & $6.26 \mathrm{~d}(2.4)$ & 111.6 \\
6 & $6.30 \mathrm{~s}$ & 92.1 & $6^{\prime}$ & & 143.5 \\
7 & & 199.2 & $7^{\prime}$ & $3.78 \mathrm{~s}$ & 56.4 \\
8 & $3.68 \mathrm{~s}$ & 56.8 & $8^{\prime}$ & $1.89 \mathrm{~s}$ & 22.4 \\
9 & $3.82 \mathrm{~s}$ & 56.4 & $2^{\prime}-\mathrm{OH}$ & $13.10 \mathrm{~s}$ & \\
10 & $3.68 \mathrm{~s}$ & 56.8 & & & \\
\hline
\end{tabular}

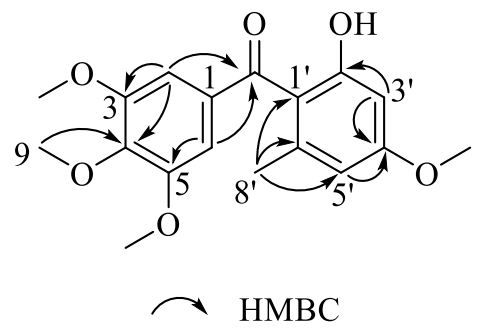

Figure 2. Key HMBC correlations of compound 1

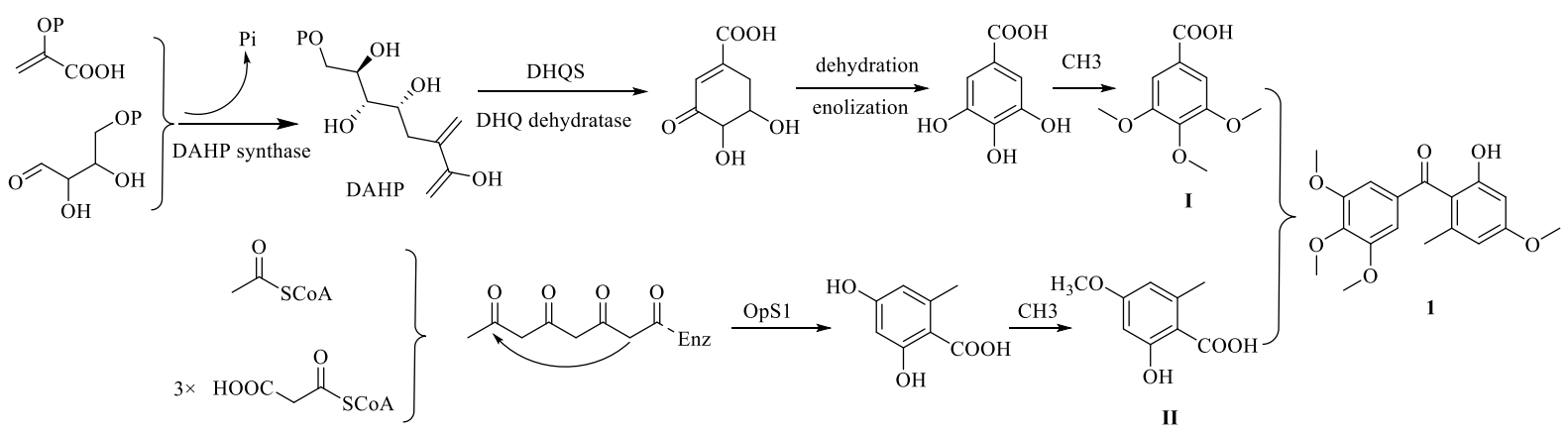

Scheme 1. Putative biosynthetic pathway of the compound 1

\section{Acknowledgments}

This project was funded by Natural Science Foundation of Hunan Province (No. 2021JJ30917), the Postgraduates Innovation Program of Central South University (Nos. 2020zzts828, 1053320192764), Open Sharing Fund for the Large-scale Instruments and Equipments of Central South University.

\section{Supporting Information}

Supporting information accompanies this paper on http://www.acgpubs.org/journal/records-ofnatural-products 


\section{ORCID}

Dekun Chen: 0000-0002-1793-1333

Sha Zhang: 0000-0001-9174-0984

Min Kuang: 0000-0002-6063-4473

Weiwei Peng: 0000-0001-8061-4800

Jianbing Tan: 0000-0002-4580-2547

Wenxuan Wang: 0000-0002-7391-2954

Fenghua Kang: 0000-0003-2323-3096

Zhenxing Zou: 0000-0003-2711-7391

Kangpin Xu: 0000-0002-0010-5430

\section{References}

[1] P. Sharma and S.P. Singh (2021). Role of the endogenous fungal metabolites in the plant growth improvement and stress tolerance, in: Fungi Bio-Prospects in Sustainable Agriculture, Environment and Nano-Technology, Ed. V. K. Sharma, M. P. Shah, A. Kumar, 3, 381-401.

[2] G.A. Strobel (2003). Endophytes as sources of bioactive products, Microbes. Infect. 5(6), 535-544.

[3] S. Kusari, S.P. Pandey and M. Spiteller (2013). Untapped mutualistic paradigms linking host plant and endophytic fungal production of similar bioactive secondary metabolites, Phytochemistry 91, 81-87.

[4] Chinese Pharmacopoeia (2020).Chinese Pharmacopoeia Commission. China Medical Science Press: Beijing, China. 1, 237.

[5] K.P. Xu, H. Zou, G.R. Liu, H.P. Long, J. Li, F.S. Li, Z.X. Zou, J.W. Kuangs, X. Xie and G.S. Tan (2011). Selaginellin M, a new selaginellin derivative from Selaginella pulvinata, J. Asian Nat. Prod. Res. 13(11), 1051-1055.

[6] T. Kishi, S. Tahara, N. Taniguchi, M. Tsuda and S. Takahashi (1991). New Perylenequinones from Shiraia bambusicola, Planta Med. 57(4), 376-379.

[7] X.M. Jia, X.H. Xu, B.C. Zhuang and H.P. Lin (2006). The progress of biological research of medicinal fungus Shiraia bambusicola, Microbiology 33(3), 147-150.

[8] Y.L. Li, Y. Xu, Q.M. Liao, M.M. Xie, H. Tao and H.L. Wang (2021). Synergistic effect of hypocrellin B and curcumin on photodynamic inactivation of Staphylococcus aureus, Microb. Biotechnol. 14(2), 692-707.

[9] T. Wang, Z. Dong, D.J. Zhou, K.L. Sun, Y.Q. Zhao, B. Wang and Y. Chen (2020). Structure and immunostimulating activity of a galactofuranose-rich polysaccharide from the bamboo parasite medicinal fungus Shiraia bambusicola, J. Ethnopharmacol. 257, 112833.

[10] Y. Zhang, Y. Luo, X.F. Tian and Z.Q. Wu (2020). Improvement on the antioxidant activity of polysaccharides by submerged fermentation of Shiraia bambusicola GDMCC 60438 (Ascomycota), Int. J. Med. Mushrooms 22(6), 605-614.

[11] A.J. Drummond and R.D. Waigh (2000). The development of microbiological methods for phytochemical screening, Recent. Res. Devel. Phytochem. 4,143-152

[12] P.C. Lim, H. Ramli, N.K. Kassim, Z. Ali, I.A. Khan, K. Shaari and A. Ismail (2019). Chemical constituents from the stem bark of Clausena excavata Burm. f, Biochem. Syst. Ecol. 82, 52-55.

[13] Q. Zeng, J. Ye, J. Ren, X.R. Cheng, J.J. Qin, H.Z. Jin and W.D. Zhang (2013). Chemical constituents from Aphanamixis grandifolia, Chem. Nat. Compd. 49(3), 486-492.

[14] H.J. Kim, C. Jin and Y.S. Lee (2007). Antioxidative activities of phenolic compounds isolated from Inonotus obliquus, Korean J. Pharmacogn. 38(2), 164-169.

[15] K. Kahlos, L. Kangas and R. Hiltunen (1989). Ergosterol Peroxide, an active compound from Inonotus radiatus, Planta Med. 55(4), 389-390.

[16] J. Zhang and X.Z. Feng (1997). Lactariolide, a new 14-membered-ring compound from Lactarius Subvellereus, Chin. Chem. Lett. 2, 135-136.

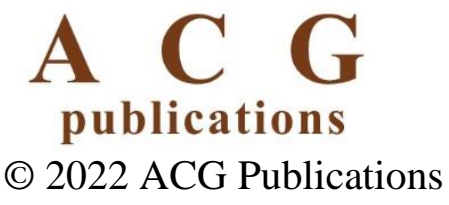

